\title{
Effects of gonadotrophin treatments on meiotic and developmental competence of oocytes in porcine primordial follicles following xenografting to nude mice
}

\author{
Hiroyuki Kaneko, Kazuhiro Kikuchi, Junko Noguchi, Manabu Ozawa, Katsuhiko Ohnuma, \\ Naoki Maedomari ${ }^{1}$ and Naomi Kashiwazaki ${ }^{1}$ \\ Genetic Diversity Department, National Institute of Agrobiological Sciences, Kannondai 2-1-2, Tsukuba, Ibaraki \\ 305-8602, Japan and ${ }^{1}$ Laboratory of Animal Reproduction, Graduate School of Veterinary Medicine, Azabu \\ University, Sagamihara, Kanagawa 229-8501, Japan
}

Correspondence should be addressed to H Kaneko; Email: kaneko@nias.affrc.go.jp

Hiroyuki Kaneko and Kazuhiro Kikuchi contributed equally to this work

\begin{abstract}
Our objective was to improve the developmental ability of oocytes in porcine primordial follicles xenografted to nude mice, by treating the host mice with gonadotrophins to accelerate follicular growth. Ovarian tissues from 20-day-old piglets, in which most of the follicles were primordial, were transplanted under the kidney capsules of ovariectomized nude mice. Gonadotrophin treatments were commenced around 60 days after vaginal cornification in the mice. Ovarian grafts were obtained 2 or 3 days after treatment with equine chorionic gonadotrophin (eCG-2 and eCG-3 groups), after porcine FSH infusion for 7 or 14 days, or after infusion of porcine FSH for 14 days with a single injection of estradiol antiserum (FSH-7, FSH-14 and FSH-14EA groups, respectively). Gonadotrophin treatments accelerated follicular growth within the xenografts compared with that in control mice given no gonadotrophins, consistent with higher $(P<0.05)$ circulating inhibin levels in the gonadotrophin-treated mice. In contrast, circulating mouse FSH levels were significantly $(P<0.05)$ depressed. We recovered large numbers of full-sized oocytes with meiotic competence to the mature stage from the eCG-3, FSH-7, and FSH-14EA, unlike in the control group. Moreover, $56 \%$ of matured oocytes with the first polar body $(n=39)$ were fertilized in vitro in the FSH-14EA group. After in vitro fertilization and subsequent culture for 7 days, one blastocyst was obtained from each of the eCG-3, FSH-7 and, FSH-14EA groups, whereas no blastocysts appeared in the other groups. Exogenous gonadotrophins not mouse FSH - stimulated the growing follicles that had developed from the primordial follicles in the xenografts: the effects were incomplete but improved to some extent the meiotic and developmental abilities of the oocytes.

Reproduction (2006) 131 279-288
\end{abstract}

\section{Introduction}

Primordial follicles act as stores for ovarian follicles and are a potential resource of oocytes for medical, agricultural, and zoological purposes. Success in the culture of primordial follicles as a method of oocyte maturation has been limited to mice (Eppig \& O'Brien 1996, O'Brien et al. 2003), since it is difficult to establish an effective culture system for large mammals, whose primordial follicles need an extremely long time to mature (Miyano 2005). Ovarian grafting provides an alternative method for the maturation of oocytes in primordial follicles (primordial oocytes) of large mammals. Recently, grafting of ovarian tissues to another site in the body (autografting) was successful in endowing the growing follicles with full developmental competence to birth in humans (Donnez et al. 2004) and primates (Lee et al. 2004). Cross-species ovarian grafting (xenografting) is advantageous for multiplication and conservation of domestic or endangered animals, because the ovaries can be collected from deceased animals and the oocytes can potentially be grown in a different species. Snow et al. (2002) demonstrated that oocytes that grow within mouse ovarian tissue xenografted to nude rats acquire the ability to generate pups. Ovarian tissues have been prepared from species phylogenetically distant from mice, including humans (Oktay et al. 1998, Weissman et al. 1999, Kim et al. 2002, Gook et al. 2003), dogs (Metcalfe et al. 2001), monkeys (Candy et al. 1995), sheep (Gosden et al. 1994), cows (Senbon et al. 2003), pigs (Kaneko et al. 2003, Kagawa et al. 2005), tammar wallaby (Mattiske et al. 2002) and common wombats 
(Cleary et al. 2003, 2004), and xenografted to immunodeficient mice. To our knowledge, only one study (Kaneko et al. 2003), in which neonatal pig ovarian tissues were xenografted, has proven that primordial oocytes can develop in the host mice and acquire fertilizing ability in vitro.

At present, no xenografting study has been successful in producing blastocysts from primordial or growing follicles of large mammals, indicating that optimal xenografting methods need to be established. One strategy for improving the developmental competence of oocytes within xenografts is to facilitate oocyte development by accelerating follicular growth with exogenous hormones. Cleary et al. (2003) indicated that greater numbers of morphologically normal oocytes were recovered from ovarian grafts of common wombats after the host mice were given follicle-stimulating hormone $(\mathrm{FSH})$ for 4 or 7 days. Treatment of host mice with FSH for over 20 weeks (Gook et al. 2003), equine chorionic gonadotrophin (eCG) for 4 weeks (Kim et al. 2002) or human menopausal gonadotrophin (hMG) for 14 days (Weissman et al. 1999) increased the number of antral follicles within human ovarian xenografts, and the former two studies showed that some antral follicles formed early corpora lutea in response to human chorionic gonadotrophin (hCG; Kim et al. 2002, Gook et al. 2003) with resumption of meiosis of the oocytes (Gook et al. 2003). We previously optimized the timing of eCG treatment of host mice in terms of follicular growth and oocyte recovery, and found that more oocytes with fertilizing ability were collected from antral follicles when eCG was given 60 days after estrus was first detected in the host mice (Kaneko et al. 2003). However, these recovered oocytes did not reach the blastocyst stage when they were matured and fertilized in vitro and immediately transferred to the oviducts of estrous-synchronized recipients gilts (Kikuchi et al. 2006). According to findings obtained in prepubertal gilts, oocytes isolated from antral follicles at least $2 \mathrm{~mm}$ in diameter resume meiosis at a higher rate than those from smaller follicles (Motlik et al. 1984), and oocytes from follicles between 3 and $5 \mathrm{~mm}$ in diameter have been proven to acquire the ability to develop to the blastocyst stage in vitro (Kikuchi et al. 2002, Marchal et al. 2002). On the other hand, the antral follicles in xenografts examined $48 \mathrm{~h}$ after eCG injection did not exceed $2 \mathrm{~mm}$ in our previous study (Kaneko et al. 2003). The above findings strongly suggest that a more effective hormone treatment to promote follicular development should be established. We therefore gave host mice several hormonal treatments, taking into account the size of the antral follicles in the xenografts at oocyte recovery, and evaluated the influence of the hormone treatments on the meiotic and developmental competence of porcine primordial oocytes under in vitro embryo-production systems.

\section{Materials and Methods Ovarian xenografting}

Protocols for the use of animals were approved by the Animal Care Committee of the National Institute of Agrobiological Sciences, Japan. Donor ovaries were dissected from 20-day-old piglets of crossbreeds (Landrace $\times$ Large White $\times$ Duroc, born at the National Institute of Livestock and Grassland Science, Tsukuba, Japan) as previously reported (Kaneko et al. 2003). At this age, primordial follicles accounted for $96 \%$ of the total number of follicles in the ovary and the rest were almost all primary follicles based on histological examinations (Kaneko et al. 2003). Immediately after removal of the ovary the cortex was cut into small pieces; these pieces were further minced into pieces of approximately $1.5 \times 1.5 \times 1.5 \mathrm{~mm}$ in saline supplemented with 668 units/ml penicillin (Sigma Chemical Co., St Louis, MO, USA) and $0.2 \mathrm{mg} / \mathrm{ml}$ streptomycin sulfate (Sigma). As recipients, 5-6-week-old female immunodeficient mice (Crlj:CD1-Foxn1 ${ }^{\text {nu}}$; Charles River Japan, Yokohama, Japan) were anesthetized and ovariectomized. Small holes were made in the mouse kidney capsule with a pair of fine forceps, and approximately 10 fragments of ovarian tissue were inserted under the capsule of each kidney. To detect the onset of vaginal cornification in the mice, vaginal smears were taken every day from 40 days after grafting.

\section{Experimental design}

Kinetic analyses of follicular growth in the prepubertal gilts estimate that growth of follicles from antrum formation to a diameter of $3 \mathrm{~mm}$ or more requires approximately 14 days (Morbeck et al. 1992). In this study, therefore, we stimulated follicular growth in the xenografts with porcine FSH for 1 or 2 weeks and the resultant follicular growth and oocytes viability were compared with those after eCG treatment described in our previous studies (Kaneko et al. 2003, Kikuchi et al. 2006). To estimate an appropriate dose of porcine FSH, we carried out a pilot study using four host mice that showed vaginal cornification 60 days before. Two host mice, implanted with one Alzet osmotic pump (model 2004, DURECT Corp, Cupertino, CA, USA) containing $31.25 \mathrm{U} / \mathrm{ml}$ porcine $\mathrm{FSH}$ (Sigma) for 1 week, had no clear enhancement of follicular growth in the xenografts. However the other two mice, implanted with a osmotic pump containing $62.5 \mathrm{U} / \mathrm{ml}$ porcine $\mathrm{FSH}$, showed the accelerated follicular growth. Therefore, a dose of $62.5 \mathrm{U} / \mathrm{ml}$ porcine FSH was chosen in this study. We also chose a dose of 4 IU eCG (PMS 1000; Nihon Zenyaku Kogyo, Koriyama, Japan), since 8-10 IU eCG injection caused an overdose and resulted in formation of many hemorrhagic follicles in the xenografts.

In the main experiment, around 60 days after the first detection of vaginal cornification in the host mice, we started giving the mice hormone treatments on the basis of our previous findings that good performance in terms of 
follicular growth and oocyte recovery was achieved when eCG was given to the host mice 60 days after first detection of vaginal cornification (Kaneko et al. 2003). Mice were randomly assigned to the following experimental groups: control $(n=11)$, eCG-2 $(n=15)$, eCG-3 $(n=16)$, FSH-7 $(n=14)$, FSH-14 $(n=11)$ and FSH-14EA $(n=10)$. Control mice received no hormone treatment. From the eCG-treated groups, grafts were recovered 2 days (eCG-2 group) or 3 days (eCG-3 group) after a single intraperitoneal injection of $4 \mathrm{IU}$ eCG. Each mouse in the FSH-treated groups was implanted with one Alzet osmotic pump (model 2004) under the skin of the back. The pump was filled with saline containing $62.5 \mathrm{U} / \mathrm{ml}$ porcine $\mathrm{FSH}$ (Sigma). Grafts were recovered from the mice after infusion of FSH for 7 days (FSH-7 group) or 14 days (FSH-14 group). To inhibit a surge-like release of luteinizing hormone, 7 days after the beginning of $\mathrm{FSH}$ infusion the mice in the FSH-14EA group received an intraperitoneal injection of $100 \mu$ l estradiol antiserum (EA) raised in a goat (Kaneko et al. 1995, 2002a), and their grafts were recovered 14 days after the beginning of FSH infusion.

\section{Blood collection and graft recovery}

Before graft recovery, mice in each group were anesthetized and bled by cardiac puncture. We also collected blood samples from five ovariectomized mice that received no ovarian grafts (OVX group). Serum was stored at $-30^{\circ} \mathrm{C}$ until it was assayed for total inhibin and $\mathrm{FSH}$. After blood sampling, cumulus-oocyte complexes (COCs) were isolated mechanically with a surgical blade in Medium 199 (with Hank's salts; Sigma; Kikuchi et al. 2002) from antral follicles in the tissue grafted under the kidney capsules. Oocytes larger than $115 \mu \mathrm{m}$ in diameter (fullsized oocytes) were selected for in vitro maturation (IVM), since oocytes larger than $115 \mu \mathrm{m}$ obtained from prepubertal gilts acquire meiotic competence (Motlik et al. 1984, Hirao et al. 1995). Ovarian grafts in the left kidney were obtained from the two mice in each group and fixed in Bouin's solution and embedded in paraffin for histological examination.

\section{In vitro maturation, in vitro fertilization (IVF) and in vitro culture (IVC) of oocytes}

Recovered COCs were matured in vitro as described previously (Kikuchi et al. 2002). Briefly, COCs were cultured for $20-22 \mathrm{~h}$ in modified North Carolina State University-37 (NCSU-37) solution (Petters \& Wells 1993) supplemented with $10 \%$ porcine follicular fluid, $0.6 \mathrm{mM}$ cysteine, $50 \mu \mathrm{M} \beta$-mercaptoethanol, $1 \mathrm{mM}$ dibutyl cAMP (Sigma), $10 \mathrm{IU} / \mathrm{ml}$ eCG (PMS 1000) and $10 \mathrm{IU} / \mathrm{ml}$ hCG (Puberogen 500 U; Sankyo, Tokyo, Japan). Subsequently, they were cultured for $24 \mathrm{~h}$ in IVM medium without the dibutyl cAMP and hormones. Maturation culture was carried out at $39^{\circ} \mathrm{C}$ under conditions of $\mathrm{O}_{2} / \mathrm{CO}_{2} / \mathrm{N}_{2}$ adjusted to 5, 5 and $90 \%$ respectively. After IVM, cumulus cells were removed by hyaluronidase treatment $(150 \mathrm{IU} / \mathrm{ml}$;
Sigma) and gentle pipetting. Oocytes with the first polar body were harvested as matured oocytes and placed in modified Pig-FM (Suzuki et al. 2002) supplemented with $2 \mathrm{mM}$ caffeine and $5 \mathrm{mg} / \mathrm{ml}$ BSA (fraction V; Sigma). Frozen epididymal spermatozoa (Kikuchi et al. 1998) were thawed and then preincubated for $15 \mathrm{~min}$ at $37^{\circ} \mathrm{C}$ in Medium 199 (with Earle's salts; Gibco, Life Technologies, Grand Island, NY, USA) adjusted to pH 7.8 (Nagai et al. 1988). A portion $(10 \mu \mathrm{l})$ of the preincubated spermatozoa was introduced into $90 \mu \mathrm{l}$ fertilization medium containing about 10 matured oocytes. The final sperm concentration was adjusted to $5 \times 10^{5} / \mathrm{ml}$. The day of IVF was defined as day 0 . After coincubation at $39^{\circ} \mathrm{C}$ under $5 \% \mathrm{O}_{2}$ for $3 \mathrm{~h}$, the oocytes were freed from the attached spermatozoa by gentle pipetting and transferred to IVC.

IVC was performed in IVC-PyrLac for days $0-2$ and in IVC-Glu for days 2-7 (Kikuchi et al. 2002). The IVC-PyrLac consisted of NCSU-37 solution (Petters \& Wells 1993) without glucose but supplemented with $50 \mu \mathrm{M} \beta$-mercaptoethanol, $0.17 \mathrm{mM}$ sodium pyruvate and $2.73 \mathrm{mM}$ sodium lactose. The IVC-Glu was NCSU-37 solution supplemented with $4 \mathrm{mg} / \mathrm{ml} \mathrm{BSA}$ and $50 \mu \mathrm{M} \beta$-mercaptoethanol.

\section{Assessment of fertilization}

To confirm the fertilization status of the recovered oocytes, 39 mature oocytes obtained from the FSH-14EA group were coincubated with the frozen-thawed boar spermatozoa for $3 \mathrm{~h}$ and were cultured for a further $5 \mathrm{~h}$ in IVC-PyrLac. They were whole-mounted on glass slides and fixed in acetic alcohol (acetic acid/methanol, 1:3). After the specimens had been stained with $1 \%$ aceto-orcein (Sigma), the nuclear status and extrusion of polar bodies were examined by phase-contrast microscopy. Fertilization of oocytes obtained from eCG-treated mice was assessed elsewhere (Kaneko et al. 2003).

\section{Embryo evaluation}

Development of IVF oocytes to the blastocyst stage was evaluated on day 7. An embryo with a clear blastocele was defined as a blastocyst, and IVF oocytes that remained at the mono-cell stage or fragmented were defined as degenerated oocytes or embryos. Embryos were fixed with acetic alcohol and stained with 1\% aceto-orcein (Sigma), and the total number of cells in each blastocyst was counted.

\section{Histological analysis}

Ovarian grafts from each group were sectioned at $7 \mu \mathrm{m}$ and stained with hematoxylin and eosin, to examine the morphological changes. Ovaries from the prepubertal gilts were examined histologically, to compare their follicular growth with that in the xenografts. 


\section{Fluoroimmunoassay for total inhibin}

Concentrations of total inhibin in the plasma of the host mice, as a marker of follicular growth, were determined by competitive fluoroimmunoassay (FIA) using europium (Eu)labeled inhibin A as a probe (Kaneko et al. 2002b). In the FIA of total inhibin, anti-bovine inhibin serum (TNDH-1; Hamada et al. 1989) was used as a primary antibody. Bovine $32 \mathrm{kDa}$ inhibin A was used for Eu-labeling and as a reference standard. Anti-inhibin serum was provided by $\mathrm{Dr}$ K Taya, Tokyo University of Agriculture and Technology, Fuchu, Tokyo, Japan; bovine $32 \mathrm{kDa}$ inhibin was provided by $\operatorname{Dr}$ Y Hasegawa, Kitasato University, Towada, Aomori, Japan. The detection limit of the FIA was $0.078 \mathrm{ng} / \mathrm{ml}$. The intra- and interassay coefficients of variation $(\mathrm{CVs})$ were 10.5 and $15.0 \%$, respectively.

\section{FIA for mouse FSH}

Concentrations of FSH in the plasma of the host mice were determined by competitive FIA using Eu-labeled rat FSH as a probe (Kaneko et al. 2002b), to assess the changes in endogenous FSH secretion after the gonadotrophin treatments. In the FIA for mouse FSH, anti-rFSH-S-11 was used as a primary antibody, $\mathrm{rFSH}-\mathrm{I}-9$ for Eu labeling and rFSH-RP-2 as a reference standard (as an assay material, a rat FSH RIA kit was provided by Dr A F Parlow, National Hormone and Peptide Program, Harbor-UCLA Medical Center, Torrance, CA, USA). Anti-rabbit immunoglobulin G (Chemicon International, Temecula, CA, USA) was used as the secondary antibody. The detection limit of the FIA was $0.39 \mathrm{ng} / \mathrm{ml}$. The intra- and interassay $\mathrm{CVs}$ were 10 and $12.5 \%$, respectively.

\section{Data analyses}

All data were subjected to analysis of variance (ANOVA), and the significance of the difference among means was determined by Duncan's multiple range test. The general linear models procedure of SAS (SAS/STAT 1988) was

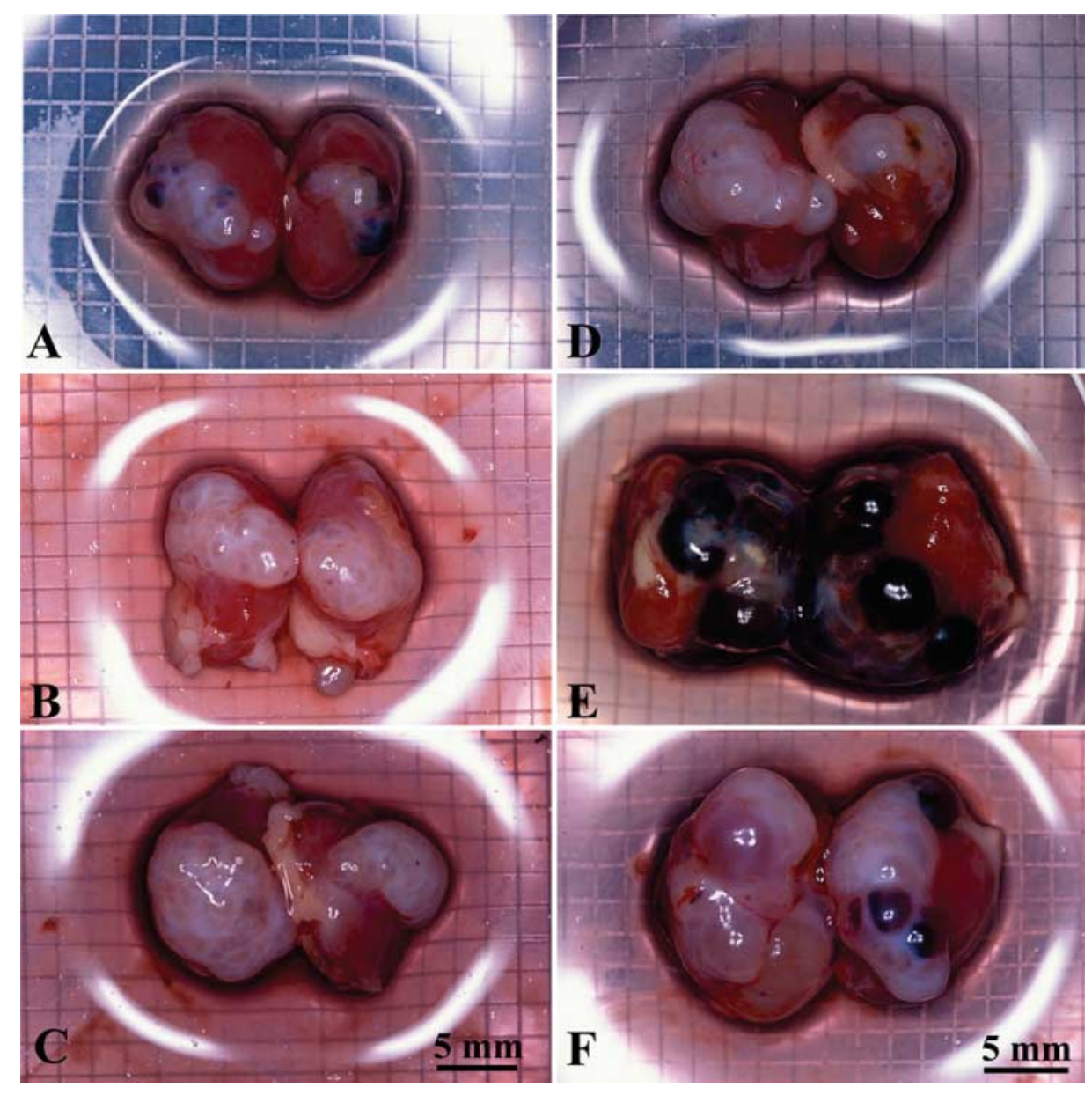

Figure 1 Porcine ovarian tissue under the renal capsule of host mice in the (A) control, (B) eCG-2, (C) eCG-3, (D) FSH-7, (E) FSH-14 and (F) FSH-14EA groups. Ovarian grafts were examined 2 (eCG-2) or 3 days (eCG-3) after eCG treatment, after infusion of porcine FSH for 7 (FSH-7) or 14 days (FSH-14), or after infusion of porcine FSH for 14 days with a single injection of estradiol antiserum 7 days after the beginning of FSH infusion (FSH-14EA). Control mice received no gonadotrophin treatment. Scale bars, $5 \mathrm{~mm}$. 


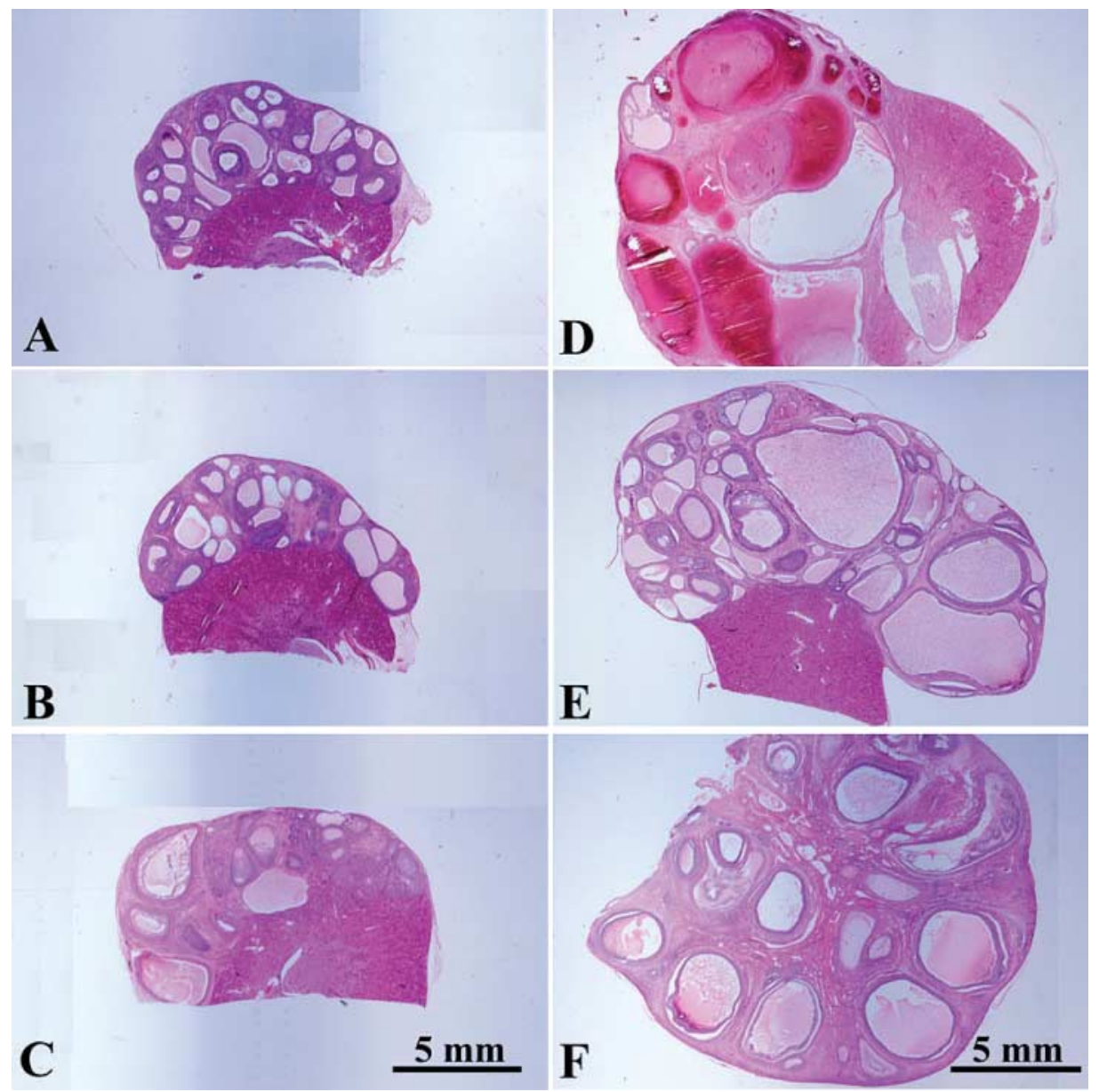

Figure 2 Histological appearance of porcine ovarian xenografts at low magnification in host mice in the (A) control, (B) eCG-3, (C) FSH-7, (D) FSH-14 and (E) FSH-14EA groups. (F) Image of an ovary section obtained from a prepubertal gilt. Examination of ovarian grafts was following treatments as described for Fig. 1. Scale bars, $5 \mathrm{~mm}$.

used for the analyses. Differences with $P$ values of $<0.05$ were considered to be significant.

\section{Results}

\section{Morphology of ovarian grafts}

Low-magnification representative features of the gross morphology and histology of the ovarian xenografts obtained from each group are shown in Figs 1 and 2 . Ovarian grafts grew and fused together under the kidney capsules of the host mice with or without gonadotrophin treatments (Fig. 1). Compared with the grafts in the control mice (Fig. 1A), ovarian grafts in mice given gonadotrophin treatments (especially FSH treatment for 7 days or more) were larger in size (Figs 1B-F). The diameters of the antral follicles in the xenografts of control and eCG-treated mice were similar and did not exceed $2 \mathrm{~mm}$ (Figs 2A and B). In contrast, treatment of host mice with $\mathrm{FSH}$ enhanced the growth of antral follicles (Figs 2C-E); the sizes of several antral follicles were similar to those of antral follicles observed in the ovaries of prepubertal gilts (Fig. 2F).
However, in the $\mathrm{FSH}-14$ group, follicular antra were frequently filled with erythrocytes (Fig. 2D). In the xenografts of the control and eCG-treated mice, the antral follicles had numerous concentric layers of mural granulosa cells and oocytes at the germinal vesicle stage surrounded by a few layers of cumulus cells (Figs $3 \mathrm{~A}$ and B). In the antral follicles of the FSH-7 and FSH-14EA groups, germinal vesicles were also observed in the oocytes, which were surrounded by a few layers of cumulus cells (Figs $3 \mathrm{C}$ and D). However, in the FSH-14 group, disorganization of cumulus cells in the larger antral follicles was evident, and the oocytes in some follicles showed germinal vesicle breakdown (Fig. 3E). The theca cells of hemorrhagic follicles in the $\mathrm{FSH}-14$ group were partly luteinized (Fig. $3 \mathrm{~F}$ ).

\section{Changes in concentrations of total inhibin and FSH in the circulation of host mice}

Circulating levels of total inhibin in ovariectomized mice that received no ovarian xenografts were close to the detection limit of the FIA (Fig. 4A). However, inhibin levels increased significantly $(P<0.05)$ in the control mice that had received xenografts. Inhibin levels in the 


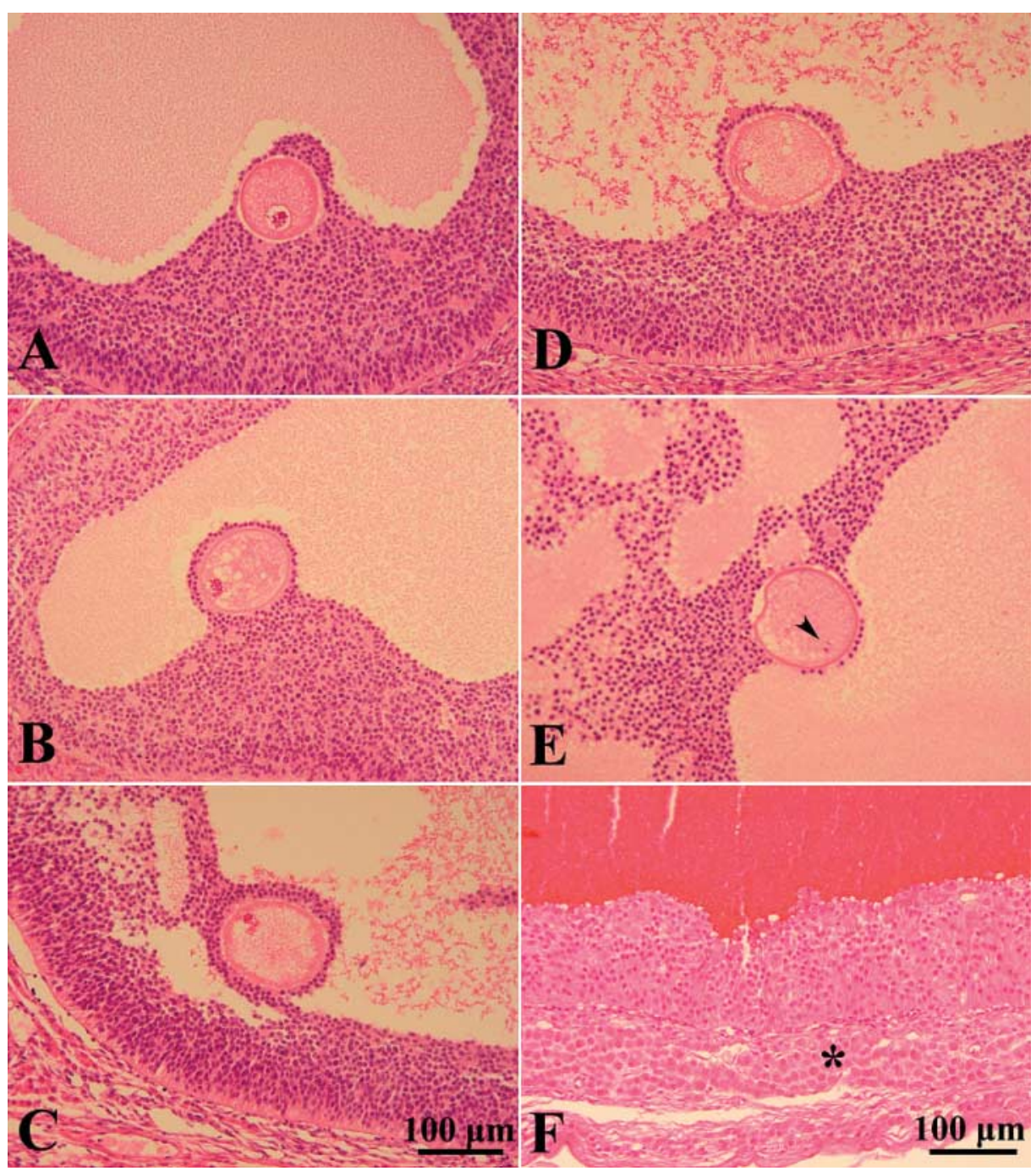

Figure 3 Histological appearance of COC and granulosa layers in xenografts of the (A) control, (B) eCG-3, (C) FSH-7, (D) FSH-14EA and (E) FSH-14 groups. (F) Image of a follicular wall obtained from the FSH-14 group. Examination of ovarian grafts was following treatments as described for Fig. 1. The arrowhead indicates resumption of meiosis. The asterisk indicates luteinization of theca layers. Scale bars, $100 \mu \mathrm{m}$.

eCG-2 and eCG-3 groups did not show a significant increase compared with those in the control mice. FSH treatment for 7 days raised inhibin levels dramatically $(P<0.01)$, and a further increase $(P<0.05)$ was noted in the FSH-14EA group. Mouse FSH levels in the circulation of ovariectomized mice were high (Fig. 4B), but significantly decreased $(P<0.01)$ in the control mice. A further decline $(P<0.05)$ in $\mathrm{FSH}$ concentrations was observed in the eCG-3 and FSH-treated groups, with the lowest levels in the FSH-7 and FSH-14EA groups.

\section{Growth and maturation of oocytes}

The number of oocytes recovered or the number of fullsized oocytes larger than $115 \mu \mathrm{m}$ per mouse was low in the control group but increased dramatically $(P<0.01)$ in the eCG-3, FSH-7, and FSH-14EA groups (Table 1).
The ratio of full-sized oocytes to the total number of oocytes ranged from 33 to $43 \%$ in these three groups but was $26 \%$ in the control group. In the control mice after IVM, a small number of oocytes had the ability to resume meiosis to the mature stage, as determined by extrusion of the first polar body. However, much greater numbers of matured oocytes were obtained from the mice in the eCG-3, FSH-7 and FSH-14EA groups $(P<0.05)$. Approximately $35 \%$ of the full-size oocytes matured in the $\mathrm{FSH}-7$ and $\mathrm{FSH}-14 \mathrm{EA}$ groups, whereas the ratio was about $20 \%$ in the control and eCG-3 groups. On the other hand, the number of oocytes was very low in the FSH-14 group, mainly because of the difficulty in collecting oocytes from hemorrhagic follicles. When 39 mature oocytes obtained from the FSH-14EA group were coincubated with frozen/thawed boar spermatozoa, 22 oocytes (56\%) 

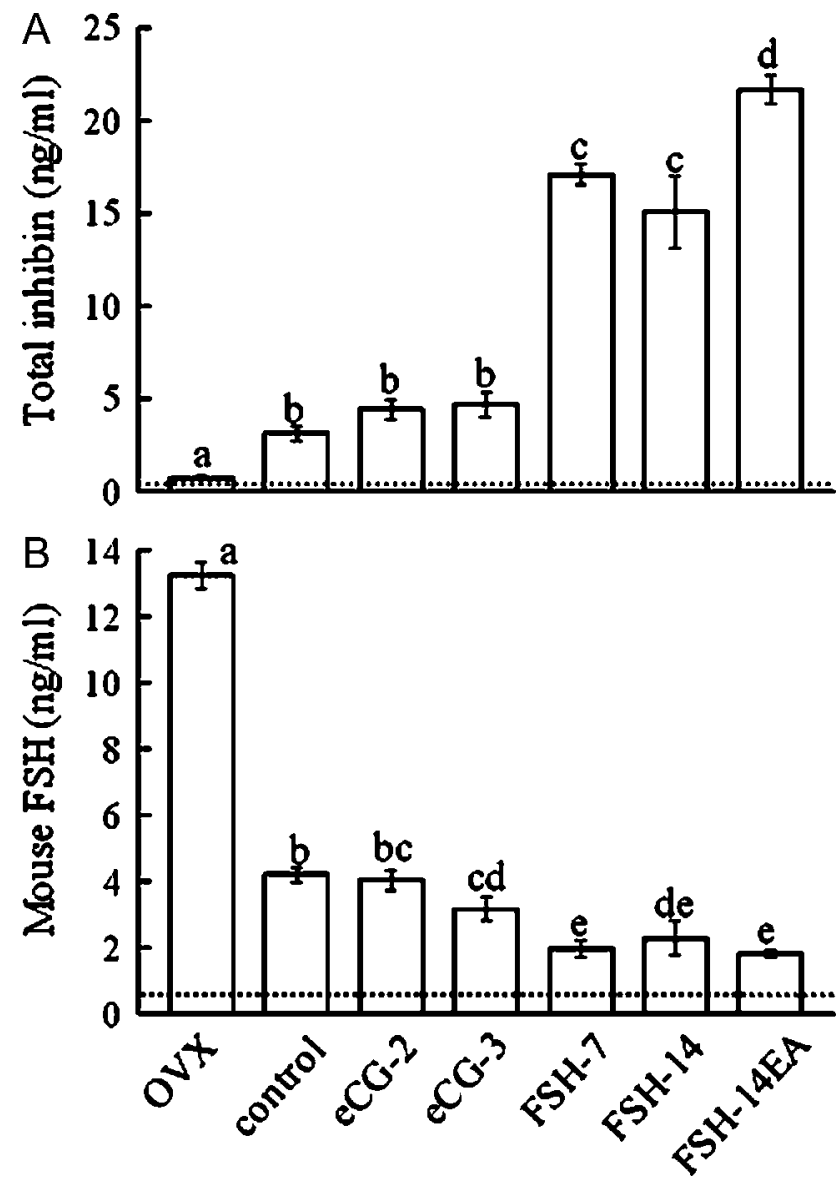

Figure 4 Circulating levels of (A) total inhibin and (B) mouse FSH in mice of the OVX, control, eCG-2, eCG-3, FSH-7, FSH-14 and FSH14EA groups. Blood samples were taken following treatments as described for Fig. 1. Samples were also collected from a control group that received no gonadotrophin treatment and from ovariectomized mice that received no ovarian grafts (OVX). Dotted lines represent the detection limits of the assays.

were penetrated by a spermatozoon (or -zoa), formed a female pronucleus and extruded the second polar body. In 19 out of 22 fertilized oocytes (86.4\%), the a sperm nucleus (or nuclei) were transformed into a male pronucleus (or pronuclei). Monospermy was noted in 12 of 22 fertilized oocytes (55\%).

\section{Development of oocytes after IVF}

Each mature oocyte obtained from the eCG-3, FSH-7 or FSH-14EA groups reached the blastocyst stage showing a clear blastocele on day 7 of IVC, but the other oocytes from the same groups remained at the mono-cell stage or showed fragmentation (Table 2 and Fig. 5A). No blastocysts appeared in the control and eCG-2 groups. The total numbers of cells in these blastocysts ranged from 16 to 30 (Table 2 and Fig. 5B).

\section{Discussion}

A major obstacle to the xenogafting of primordial oocytes in large mammals is the difficulty in collecting viable oocytes from the host mice for subsequent in vitro maturation and fertilization. Therefore, it has been unclear whether primordial oocytes grown in xenografts can develop to the blastocyst stage after IVC. We previously reported that xenografting of neonatal pig ovarian tissue with subsequent eCG treatment of the host mice enabled us to obtain in vitro-fertilizable oocytes from xenografted primordial follicles. However, these recovered oocytes did not reach the blastocyst stage when they were matured and fertilized in vitro, and immediately transferred to the oviducts of estrous-synchronized recipients gilts (Kikuchi et al. 2006). To our knowledge, this study has shown for the first time that primordial oocytes of large mammals can be developed to the blastocyst stage by a combination of xenografting and culture by adding hormone treatment of the host mice. As a first step, we tried several hormonal treatments of the host mice to promote oocyte growth by acceleration of follicular growth in the grafted porcine neonatal ovarian tissue. Then we assessed the developmental competence of the recovered oocytes with culture.

Many more full-sized oocytes ( $\geqq 115 \mu \mathrm{m}$ ) with meiotic competence were recovered from the mice in the eCG-3, FSH-7 and FSH-14EA groups than from those in the control group. These results clearly indicate that the three gonadotrophin treatments of the host mice improved the

Table 1 Numbers and meiotic competence of porcine oocytes recovered from host mice that had received hormonal treatment.

\begin{tabular}{|c|c|c|c|c|}
\hline Group $^{a}$ & No. of mice & No. of oocytes recovered ${ }^{b}$ & No. of oocytes larger than $115 \mu \mathrm{m}^{c}$ & No. of oocytes in metaphase II stage ${ }^{\mathrm{d}}$ \\
\hline Control & 9 & $70.7 \pm 16.8^{\mathrm{e}}(636)$ & $18.4 \pm 5.3^{\mathrm{e}}(166)$ & $3.4 \pm 0.9^{\mathrm{e}}(31)$ \\
\hline eCG-2 & 13 & $76.5 \pm 14.8^{\mathrm{e}}(995)$ & $22.9 \pm 4.3^{\mathrm{e}}(297)$ & $7.7 \pm 1.6^{\mathrm{ef}}(100)$ \\
\hline eCG-3 & 14 & $176.3 \pm 31.7^{\mathrm{fg}}(2468)$ & $66.5 \pm 11.0^{f}(931)$ & $13.6 \pm 3.3^{\mathrm{fg}}(191)$ \\
\hline $\mathrm{FSH}-7$ & 12 & $180.3 \pm 23.8^{g}(2164)$ & $60.3 \pm 11.2^{f}(723)$ & $20.8 \pm 4.1^{g}(250)$ \\
\hline FSH-14 & 9 & $37.3 \pm 9.4^{\mathrm{e}}(336)$ & $6.9 \pm 1.9^{\mathrm{e}}(62)$ & $2.8 \pm 0.7^{\mathrm{e}}(25)$ \\
\hline FSH-14EA & 8 & $114.0 \pm 21.2^{f}(917)$ & $49.3 \pm 9.1^{f}(394)$ & $16.1 \pm 4.7^{\mathrm{fg}}(129)$ \\
\hline
\end{tabular}

\footnotetext{
${ }^{\text {a }}$ The eCG-2 or -3 group received 4 IU eCG and the grafts were examined 2 (eCG-2) or 3 days (eCG-3) later; the FSH-7 or -14 group received porcine $\mathrm{FSH}$ for 7 (FSH-7) or 14 days ( $\mathrm{FSH}-14$ ); the FSH-14EA group received porcine $\mathrm{FSH}$ for 14 days with a single injection of estradiol antiserum 7 days after the beginning of FSH infusion; control mice received no hormone treatment.

${ }^{b-d}$ The number of oocytes in each category is represented by mean \pm S.E.M. per mouse followed by the total number (in parentheses).

${ }^{\mathrm{e}-\mathrm{g}}$ Values in the same column without common superscripts are significantly different.
} 
Table 2 In vitro development of porcine oocytes recovered from host mice that had received hormonal treatment.

\begin{tabular}{lcc}
\hline Group $^{\mathrm{a}}$ & $\begin{array}{c}\text { No. of mature oocytes } \\
\text { for IVF }^{\mathrm{b}}\end{array}$ & $\begin{array}{c}\text { No. of oocytes developed } \\
\text { to blastocyst }^{\mathrm{C}}\end{array}$ \\
\hline Control & 31 & 0 \\
eCG-2 & 100 & 0 \\
eCG-3 & 115 & $1(23)$ \\
FSH-7 & 163 & $1(16)$ \\
FSH-14EA & 113 & $1(30)$ \\
\hline
\end{tabular}

${ }^{\mathrm{a}}$ The eCG-2 or -3 group received $4 \mathrm{IU}$ eCG and the grafts were examined 2 (eCG-2) or 3 days (eCG-3) later; the FSH-7 group received porcine $\mathrm{FSH}$ for 7 days; the FSH-14EA group received porcine FSH for 14 days with a single injection of estradiol antiserum 7 days after the beginning of FSH infusion; control mice received no hormone treatment.

${ }^{\mathrm{b}}$ Oocytes with the first polar body were subjected IVF.

${ }^{\mathrm{c}}$ The no. of oocytes is followed by total number of cells in the blastocysts (in parentheses).

meiotic competence of the oocytes by promoting oocyte growth within the xenografts. These treatments probably induced a similar increase in the total number of antral follicles, judging from the total numbers of oocytes recovered; however, about $35 \%$ of the full-size oocytes matured

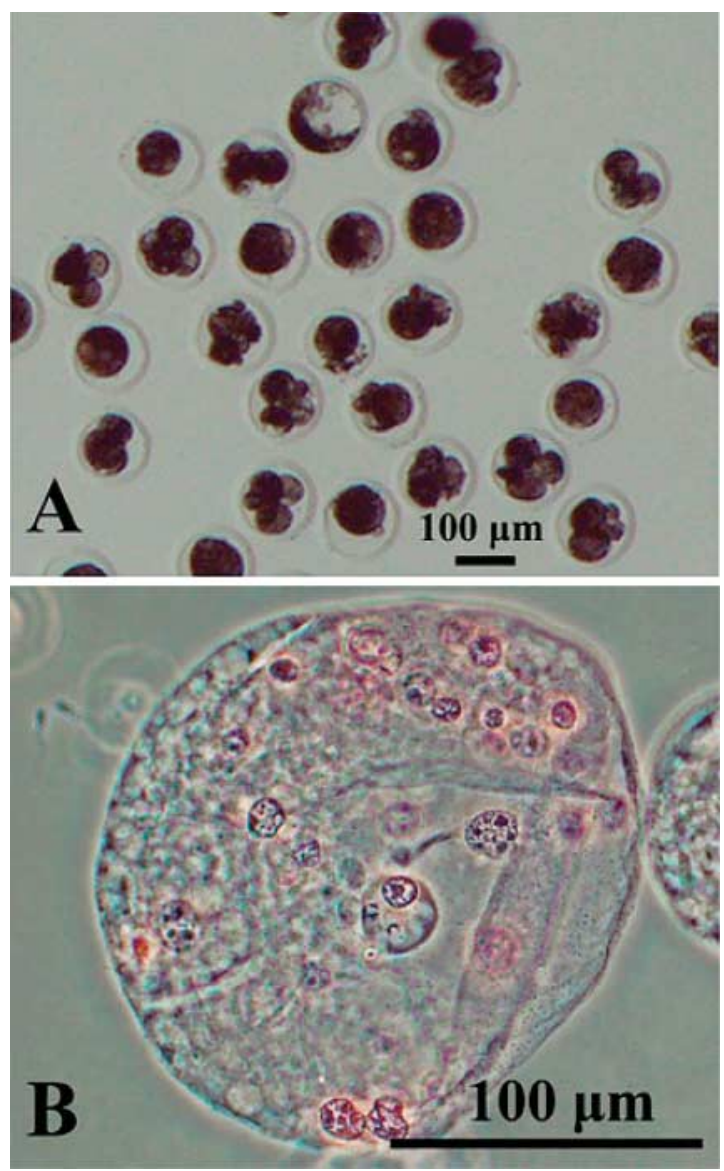

Figure 5 Developmental competence of porcine oocytes recovered from mice in the FSH-14EA group. (A) Results of IVF/IVC on day 7 of IVC (day $0=$ day of IVF). (B) A blastocyst appeared on day 7 of IVC. Scale bars, $100 \mu \mathrm{m}$. in the $\mathrm{FSH}-7$ and $\mathrm{FSH}-14 \mathrm{EA}$ groups, whereas this ratio was $20 \%$ in the eCG-3 group. The difference in maturation rates between $\mathrm{FSH}$ and eCG treatments may be attributed to the difference in the follicular response after treatment. It has been demonstrated that larger-diameter follicles contain oocytes with higher meiotic or developmental potential in pigs (Motlik et al. 1984, Luca et al. 2002, Marchal et al. 2002), cattle (Lonergan et al. 1994, Blondin \& Sirard 1995, Lequarre et al. 2005) and monkeys (Gilchrist et al. 1997). The ability of the oocyte to develop to the blastocyst stage is thought to be a suitable indication of competence. The appearance of blastocysts in the eCG-3, FSH-7 and FSH-14EA groups suggests that gonadotrophin treatment of the host mice can endow oocytes grown in the xenografts with developmental ability. The oocyte accumulates RNA molecules and proteins in its cytoplasm during the growth phase, and timely use of such stored molecules is essential for oocyte maturation, fertilization and subsequent embryonic transcription before genomic activation (Gandolfi \& Gandolfi 2001). Gonadotrophin treatments may improve - albeit inadequately - this cytoplasmic function of oocytes within the xenografts by promoting follicular growth.

Our results clearly indicate that gonadotrophin treatments alter the hormonal environment in the host mice. It is apparent from our results that endogenous $\mathrm{FSH}$ secretion in control mice was regulated by inhibin produced from the surviving ovarian grafts. FSH levels in the control mice were likely to be within a range that maintained early growth of the antral follicles in the xenografts, since several antral follicles were morphologically normal and some oocytes had meiotic ability in vitro. After treatment with gonadotrophins, especially with FSH, the ovarian grafts showed increased inhibin production, probably in association with increased estradiol production, and this had further negative-feedback effects on mouse pituitary FSH secretion. A similar reciprocal relationship between inhibin and $\mathrm{FSH}$ has been observed in FSH- or eCG-treated domestic animals (McNeilly et al. 1989, Kaneko et al. 1992). The fact that FSH secretion was severely suppressed in mice of the eCG-3- and porcine FSH-treated groups strongly suggests that, in these groups, follicular growth is stimulated or maintained largely by exogenous gonadotrophins, not by endogenous mouse FSH.

It is widely accepted that the occurrence of a surge of luteinizing hormone, triggered by increased circulating estradiol levels, induces preovulatory changes in large antral follicles, including invasion of blood into the antrum, luteinization of the follicular wall and resumption of meiosis of oocytes. In the present study, luteinization of granulosa and theca cells, invasion of blood into the follicular cavity and germinal vesicle breakdown of oocyte nucleus were frequently observed within the xenografts of the $\mathrm{FSH}-14$ group. These histological changes are similar to those that occur in the large antral follicles of human xenografts after treatment with hCG (Kim et al. 2002, 
Gook et al. 2003). The observations made in the FSH-14 group suggest that a surge-like release of luteinizing hormone might occur during the 14 days of FSH treatment, probably in response to increased estradiol levels in the circulation. This hypothesis is supported by the finding that injection of estradiol antiserum (in the FSH-14EA group) reduced the rate of occurrence of hemorrhagic follicles.

Although our results show that exogenous hormone treatments have positive effects on the developmental ability of porcine primordial oocytes xenografted to host mice, there remain many problems to be resolved. The ratio of mature oocytes to full-size oocytes was about 35\% and the percentage of mature oocytes that could develop to the blastocyst stage was about $1 \%$. These ratios were lower than we found previously after IVM (70\%; Kikuchi et al. 1999a, 2002) or IVC $(20 \%$ in Kikuchi et al. 2002; $17 \%$ in Suzuki et al. 2006) of oocytes collected from the prepubertal gilts using the same culture systems. The present and previous (Kaneko et al. 2003) studies confirm that more than $50 \%$ of mature oocytes, obtained from host mice that received eCG or porcine FSH treatment, had the abilities of fertilization and of transformation of a sperm nucleus to a male pronucleus. Furthermore, we observed a higher incidence of monospermic fertilization. The above results suggest that the nuclear maturation of oocytes grown in the xenografts can be attained but cystoplasmic maturation of the oocytes to the blastocyst stage is difficult to be accomplished by the present hormone treatments. The morphology of COCs in the xenografts may partly account for the low competence of the oocytes grown in host mice. In our xenografts, the oocytes were surrounded by one to three layers of cumulus cells, whereas the COCs obtained from prepubertal gilts and used for in vitro production of blastocysts have more than several layers of cumulus cells (Kikuchi et al. 1999b, Kikuchi et al. 2002). A clear relationship between the quality of the COCs (number of layers or number of follicle cells around the oocytes) and fertilization or embryo development following culture has been observed in cows (Lonergan et al. 1994) and pigs (Nagai et al. 1993).

In conclusion, we demonstrated that gonadotrophin treatment of host mice increased the meiotic ability of the oocytes grown from the porcine primordial oocytes within the xenografts. Oocytes that matured after IVM could reach the blastocyst stage after IVC, although their rate of occurrence was very low. The above results suggest that ovarian xenografting, in combination with hormone treatment of the host mice and subsequent culture of the oocytes, may be able to endow primordial oocytes with developmental competence.

\section{Acknowledgements}

This study was supported in part by a Grant-in-Aid for Scientific Research (17380170) from the Japanese Society for Promotion of Science. We thank Dr A F Parlow, National
Hormone and Peptide Program, Harbor-UCLA Medical Center, Torrance, CA, USA, for providing the rat FSH RIA kit. We also thank Dr K Taya, Tokyo University of Agriculture and Technology, Tokyo, Japan, for providing anti-inhibin serum and $\operatorname{Dr}$ Y Hasegawa, Kitasato University, Aomori, Japan, for providing bovine $32 \mathrm{kDa}$ inhibin. We thank Ms T Aoki for technical assistance. The authors declare that there is no conflict of interest that would prejudice the impartiality of this scientific work.

\section{References}

Blondin P \& Sirard MA 1995 Oocyte and follicular morphology as determining characteristics for developmental competence in bovine oocytes. Molecular Reproduction and Development 41 54-62.

Candy CJ, Wood MJ \& Whittingham DG 1995 Follicular development in cryopreserved marmoset ovarian tissue after transplantation. Human Reproduction $102334-2338$.

Cleary M, Paris MC, Shaw J, Jenkin G \& Trounson A 2003 Effect of ovariectomy and graft position on cryopreserved common wombat (Vombatus ursinus) ovarian tissue following xenografting to nude mice. Reproduction, Fertility and Development 15333 -342.

Cleary M, Shaw JM, Jenkin G \& Trounson AO 2004 Influence of hormone environment and donor age on cryopreserved common wombat (Vombatus ursinus) ovarian tissue xenografted into nude mice. Reproduction, Fertility and Development 16 699-707.

Donnez J, Dolmans MM, Demylle D, Jadoul P, Pirard C, Squifflet J et al. 2004 Livebirth after orthotopic transplantation of cryopreserved ovarian tissue. Lancet 364 1405-1410.

Eppig J \& O'Brien MJ 1996 Development in vitro of mouse oocytes from primordial follicles. Biology of Reproduction 54 197-207.

Gandolfi TA \& Gandolfi F 2001 The maternal legacy to the embryo: cytoplasmic components and their effects on early development. Theriogenology 55 1255-1276.

Gilchrist RB, Nayudu PL \& Hodges JK 1997 Maturation, fertilization, and development of marmoset monkey oocytes in vitro. Biology of Reproduction 56 238-246.

Gook DA, Edgar DH, Borg J, Archer J, Lutjen PJ \& McBain JC 2003 Oocyte maturation, follicle rupture and luteinization in human cryopreserved ovarian tissue following xenografting. Human Reproduction $181772-1781$.

Gosden RG, Boulton MI, Grant K \& Webb R 1994 Follicular development from ovarian xenografts in SCID mice. Journal of Reproduction and Fertility 101 619-623.

Hamada T, Watanabe G, Kokuho T, Taya K, Sasamoto S, Hasegawa Y et al. 1989 Radioimmunoassay of inhibin in various mammals. Journal of Endocrinology 122 697-704.

Hirao Y, Tsuji Y, Miyano T, Okano A, Miyake M, Kato S \& Moor RM 1995 Association between p34 ${ }^{\text {cdc2 }}$ levels and meiotic arrest in pig oocytes during early growth. Zygote 3 325-332.

Kagawa N, Sakurai Y, Miyano T \& Manabe N 2005 Effects of longterm grafting on follicular growth in porcine ovarian cortical grafts xenoplanted to severe combined immunodeficient (SCID) mice. Journal of Reproduction and Development 51 77-85.

Kaneko H, Watanabe G, Taya K \& Sasamoto S 1992 Changes in peripheral levels of bioactive and immunoreactive inhibin, estradiol$17 \beta$, progesterone, luteinizing hormone, and follicle-stimulating hormone associated with follicular development in cows induced to superovulate with equine chorionic gonadotropin. Biology of Reproduction 47 76-82.

Kaneko H, Nakanishi Y, Akagi S, Arai K, Taya K, Watanabe G et al. 1995 Immunoneutralization of inhibin and estradiol during the follicular phase of the estrous cycle in cows. Biology of Reproduction $53931-939$.

Kaneko H, Todoroki J, Noguchi J, Kikuchi K, Mizoshita K, Kubota C \& Yamakuchi H 2002a Perturbation of estradiol-feedback control 
of luteinizing hormone secretion by immunoneutralization induces development of follicular cysts in cattle. Biology of Reproduction 67 1840-1845.

Kaneko H, Noguchi J, Kikuchi K, Todoroki J \& Hasegawa Y 2002b Alterations in peripheral concentrations of inhibin $A$ in cattle studied using a time-resolved immunofluorometric assay: relationship with estradiol and follicle-stimulating hormone in various reproductive conditions. Biology of Reproduction 67 38-45.

Kaneko H, Kikuchi K, Noguchi J, Hosoe M \& Akita T 2003 Maturation and fertilization of porcine oocytes from primordial follicles by a combination of xenografting and in vitro culture. Biology of Reproduction 69 1488-1493.

Kikuchi K, Nagai T, Kashiwazaki N, Ikeda H, Noguchi J, Shimada A, Soloy E \& Kaneko H 1998 Cryopreservation and ensuing in vitro fertilization ability of boar spermatozoa from epididymides stored at $4^{\circ} \mathrm{C}$. Theriogenology $50615-623$.

Kikuchi K, Nagai T, Ding J, Yamauchi J, Noguchi J \& Izaike J 1999a Cytoplasmic maturation for activation of pig follicular oocytes cultured and arrested at metaphase I. Journal of Reproduction and Fertility 116 143-156.

Kikuchi K, Kashiwazaki N, Noguchi J, Shimada A, Takahashi R, Hirabayashi M et al. 1999b Developmental competence, after transfer to recipients, of porcine matured, fertilized, and cultured in vitro. Biology of Reproduction $60336-340$.

Kikuchi K, Onishi A, Kashiwazaki N, Iwamoto M, Noguchi J, Kaneko H et al. 2002 Successful piglet production after transfer of blastocysts produced by a modified in vitro system. Biology of Reproduction 66 1033-1041.

Kikuchi K, Kaneko H, Nakai M, Noguchi J, Ozawa M, Ohnuma K \& Kashiwazaki N 2006 In vitro and in vivo developmental ability of oocytes derived from porcine primordial follicles xenografted into nude mice. Journal of Reproduction and Development(in press).

Kim SS, Soules MR \& Battaglia DE 2002 Follicular development, ovulation, and corpus luteum formation in cryopreserved human ovarian tissue after xenotransplantation. Fertility and Sterility 78 77-82.

Lee DM, Yeoman RR, Battaglia DE, Stouffer RL, Zelinski-Wooten MB, Fanton JW \& Wolf DP 2004 Live birth after ovarian tissue transplant. Nature 428 137-138.

Lequarre AS, Vigneron C, Ribaucour F, Holm P, Donnay I, DalbiesTran R et al. 2005 Influence of antral follicle size on oocyte characteristics and embryo development in the bovine. Theriogenology 63 841-859.

Lonergan P, Monaghan P, Rizos D, Boland MP \& Gordon I 1994 Effect of follicle size on bovine oocyte quality and developmental competence following maturation, fertilization, and culture in vitro. Molecular Reproduction and Development 37 48-53.

Luca X, Martinez EA, Roca J, Vazquez JM, Gil MA, Pastor LM \& Alabart JL 2002 Relationship between antral follicle size, oocyte diameters and nuclear maturation of immature oocytes in pigs. Theriogenology 58 871-885.

Marchal R, Vigneron C, Perreau C, Bali-Papp A \& Mermillod P 2002 Effect of follicular size on meiotic and developmental competence of porcine oocytes. Theriogenology 57 1523-1532.

Mattiske D, Shaw G \& Shaw JM 2002 Influence of donor age on development of gonadal tissue from pouch young of the tammar wallaby, Macropus eugenii, after cryopreservation and xenografting into mice. Reproduction 123 143-153.
McNeilly AS, Swanston IA, Crow W, Tsonis CG \& Baird DT 1989 Changes in the plasma concentrations of inhibin throughout the normal sheep oestrous cycle and after the infusion of FSH. Journal of Endocrinology 120 295-305.

Metcalfe SS, Shaw JM \& Gunn IM 2001 Xenografting of canine ovarian tissue to ovariectomized severe combined immunodeficient (SCID) mice. Journal of Reproduction and Fertility Supplement 57 323-329.

Miyano T 2005 In vitro growth of mammalian oocytes. Journal of Reproduction and Development 51 169-176.

Morbeck DE, Esbenshade KL, Flowers WL \& Britt JH 1992 Kinetics of follicle growth in the prepubertal guilt. Biology of Reproduction $47485-491$.

Motlik J, Crozet N \& Fulka J 1984 Meiotic competence in vitro of pig oocytes isolated from early antral follicles. Journal of Reproduction and Fertility 72 323-328.

Nagai T, Takahashi T, Masuda H, Shioya Y, Kuwayama M, Fukushima M et al. 1988 In vitro fertilization of pig oocytes by frozen boar spermatozoa. Journal of Reproduction and Fertility 84 585-591.

Nagai T, Ding J \& Moor RM 1993 Effect of follicle cells and steroidogenesis on maturation and fertilization in vitro of pig oocytes. Journal of Experimental Zoology 266 146-151.

O'Brien MJ, Pendola JK \& Eppig JJ 2003 A revised protocol for in vitro development of mouse oocytes from primordial follicles dramatically improves their developmental competence. Biology of Reproduction 68 1682-1686.

Oktay K, Newton H, Mullan J \& Gosden RG 1998 Development of human primordial follicles to antral stages in SCID/hpg mice stimulated with follicle stimulating hormone. Human Reproduction 13 1133-1138.

Petters RM \& Wells KD 1993 Culture of pig embryos. Journal of Reproduction and Fertility Supplement 48 61-73.

SAS/STAT 1988 User's Guide Release 6.03, pp. 549-640. Cary, NC: SAS Institute.

Senbon S, Ota A, Tachibana M \& Miyano T 2003 Bovine oocytes in secondary follicles grow and acquire meiotic competence in severe combined immunodeficient mice. Zygote 11 139-149.

Snow M, Cox S-L, Jenkin G, Trounson A \& Shaw J 2002 Generation of live young from xenografted mouse ovaries. Science 2972227.

Suzuki K, Asano A, Eriksson B, Niwa K, Nagai T \& RodriguezMartinez H 2002 Capacitation status and in vitro fertility of boar spermatozoa: effects of seminal plasma, cumulus-oocytecomplexes-conditioned medium and hyaluronan. International Journal of Andrology 25 84-93.

Suzuki M, Misumi K, Ozawa M, Noguchi J, Kaneko H, Ohnuma K et al. 2006 Successful piglet production by IVF of oocytes matured in vitro using NCSU-37 supplemented with fetal bovine serum. Theriogenology 65 374-386.

Weissman A, Gotlieb L, Colgan T, Jurisicova A, Greenblatt EM \& Casper RF 1999 Preliminary experience with subcutaneous human ovarian cortex transplantation in the NOD-SCID mouse. Biology of Reproduction $601462-1467$.

Received 7 September 2005

First decision 10 October 2005

Revised manuscript received 18 October 2005

Accepted 31 October 2005 